\title{
Interferência de Plantas Daninhas no Acúmulo de Nutrientes e no Crescimento de Plantas de Abacaxi ${ }^{1}$
}

\author{
Weed Interference in Nutrient Accumulation and Pineapple Crop Growth
}

CATUNDA, M.G. ${ }^{2}$, FREITAS, S.P. ${ }^{3}$, SILVA, C.M.M. ${ }^{4}$, CARVALHO, A.J.R.C. ${ }^{3}$ e SOARES, L.M.S. ${ }^{5}$

\begin{abstract}
RESUMO - O objetivo deste trabalho foi verificar os efeitos da interferência de Bidens pilosa, Cyperus rotundus e Digitaria horizontalis, em cinco densidades (0, 10, 20, 30 e 40 plantas por vaso), nos teores de nitrogênio, fósforo, potássio, cálcio e magnésio presentes na folha $\mathrm{D}$ e no comprimento desta, aos 30, 60 e 90 dias após o plantio do abacaxizeiro. Em geral, os teores dos nutrientes na folha $\mathrm{D}$ da cultura reduziram em razão do aumento da densidade das espécies de plantas daninhas, e os elementos mais extraídos aos 30 dias foram fósforo e potássio; além disso, C. rotundus e D. horizontalis foram as espécies que mais interferiram no teor nutricional do abacaxizeiro. Com relação ao comprimento da folha $\mathrm{D}$, verificou-se comportamento análogo, ou seja, à medida que se aumentou a densidade de plantas daninhas, o valor dessa variável foi reduzido.
\end{abstract}

Palavras-chave: Bidens pilosa, Cyperus rotundus, densidade, Digitaria horizontalis.

\begin{abstract}
The objective of this study is to verify the interference of Bidens pilosa, Cyperus rotundus and Digitaria horizontalis, under five densities $(0,10,20,30$ and 40 plants per vase), of nitrogen, phosphorus, potassium, calcium and magnesium contents present in the $D$ leaf, and in its length, at 30,60 and 90 days after pineapple crop planting. In general, the nutrient contents in the $D$ leaf of pineapple decreased with increasing weed density, but the most extracted elements at 30 days were phosphorus and potassium, respectively; besides, C. rotundus and $\mathbf{D}$. horizontalis were the species that most interfered in the nutritional content of the pineapple crop. In relation to D leaf length, an analogous behavior was verified, i.e., weed density increased as $D$ leaf length value decreased.
\end{abstract}

Keywords: Bidens pilosa, Cyperus rotundus, density, Digitaria horizontalis.

\section{INTRODUÇÃO}

Dentre as várias espécies de plantas daninhas presentes nos plantios comerciais de abacaxi, Cyperus rotundus, devido à sua alta eficiência na assimilação do $\mathrm{CO}_{2}$ atmosférico e, conseqüentemente, à conversão deste em carboidrato (Elmore \& Paul, 1983), associada à sua alta capacidade de infestação e de liberação de aleloquímicos no solo (Quayyum et al., 2000), pode causar interferência negativa no crescimento e desenvolvimento da cultura; a sua importância fica ainda mais evidente por ser uma espécie de difícil controle químico e/ou mecânico.

Outras espécies, como Bidens pilosa, podem promover elevada extração de nutrientes; quanto maior a extração, maior será o grau de competição nutricional com a cultura de interesse. Sob densidade de cinco plantas por vaso de $B$. pilosa, o conteúdo relativo de nitrogênio, fósforo, potássio, cálcio e magnésio é cerca de $4,14,6,7$ e 9 vezes maior, respectivamente, nessa espécie do que na parte aérea de plantas de café cultivadas sem a

\footnotetext{
1 Recebido para publicação em 23.3.2005 e na forma revisada em 24.2.2006.

2 Doutoranda, UENF-CBB/LBCT; ${ }^{3}$ Prof., UENF-CCTA/LFIT; ${ }^{4}$ Doutorando, UENF-CCTA/LFIT, Bolsista do CNPq; ${ }^{5}$ Téc. Nível Superior, UENF-CCTA/LFIT, Universidade Estadual do Norte Fluminense - UENF, 28013-602 Campos dos Goytacazes-RJ.
} 
interferência desta planta daninha (Ronchi et al., 2003). Além disso, Procópio et al. (2004) verificaram que essa espécie apresenta elevada eficiência na utilização do nitrogênio absorvido, convertendo-o em biomassa. Guanto a Digitaria horizontalis, verifica-se que a competição desta, sob densidade de 240 plantas $\mathrm{m}^{-2}$, com a cultura da melancia pode, por exemplo, promover reduções significativas (próximas a 40\%) na produção de frutos (Maciel et al., 2002), provavelmente em decorrência da maior alocação de nutrientes por parte da planta daninha, dado o maior contingente populacional desta.

Em virtude do exposto, este trabalho visou avaliar a interferência de $B$. pilosa, $C$. rotundus e $D$. horizontalis, sob diferentes densidades, nos teores de nitrogênio, fósforo, potássio, cálcio e magnésio na folha $\mathrm{D}$ de plantas de abacaxi (Ananas comossus) e sobre o comprimento desta.

\section{MATERIAL E MÉTODOS}

O experimento foi realizado em casa de vegetação em delineamento inteiramente casualizado, com quatro repetições; as mudas de abacaxizeiro (uma por recipiente) foram cultivadas em vasos contendo $15 \mathrm{~L}$ de substrato composto por solo, areia e esterco bovino na proporção de 1:2:1, respectivamente, cujas características físico-químicas estão apresentadas na Tabela 1. Foi avaliada a interferência de três espécies de plantas daninhas - Bidens pilosa, Cyperus rotundus e Digitaria horizontalis - sob cinco densidades $(0,10,20$, 30 e 40 plantas por vaso), as quais foram semeadas diretamente nos vasos, após prégerminação.

Aos 30, 60 e 90 dias após a instalação do experimento procedeu-se à retirada das folhas $\mathrm{D}$ de cada abacaxizeiro - folha mais jovem entre as folhas adultas e a mais ativa fisiologicamente (Cunha et al., 1999; Figura 1) - para avaliação do comprimento e dos teores nutricionais nestas. Para isso, as folhas coletadas foram limpas com algodão embebido em água desionizada e, em seguida, colocadas em sacos de papel e desidratadas em estufa sob circulação forçada de ar por 72 horas, a $70 \pm 2{ }^{\circ} \mathrm{C}$. Todo o material foi posteriormente moído, homogeneizado e amostrado, para avaliação dos teores nutricionais. A determinação de N, $\mathrm{P}, \mathrm{K}, \mathrm{Ca}$ e $\mathrm{Mg}$ nas amostras foi realizada mediante a submissão destas à digestão nitroperclórica $\left(\mathrm{HNO}_{3}\right.$ e $\mathrm{HClO}_{4}$ ) (Bull \& Rosolem, 1989). O nitrogênio total foi avaliado segundo método de micro-Kjeldahl (Mills \& Jones Jr., 1996), após digestão sulfúrica do tecido vegetal; para o fósforo, empregou-se o método do molibdato baseado em colorimetria; enquanto para potássio, cálcio e magnésio, a espectrofotometria de emissão de chama foi utilizada.

Para interpretação dos resultados, calculou-se a porcentagem relativa de redução no teor dos nutrientes na folha $\mathrm{D}$ do abacaxizeiro, atribuindo-se o valor de $100 \%$ ao teor de nutrientes verificado nas plantas de abacaxi que cresceram livres de interferência. Para obtenção do percentual relativo de acúmulo
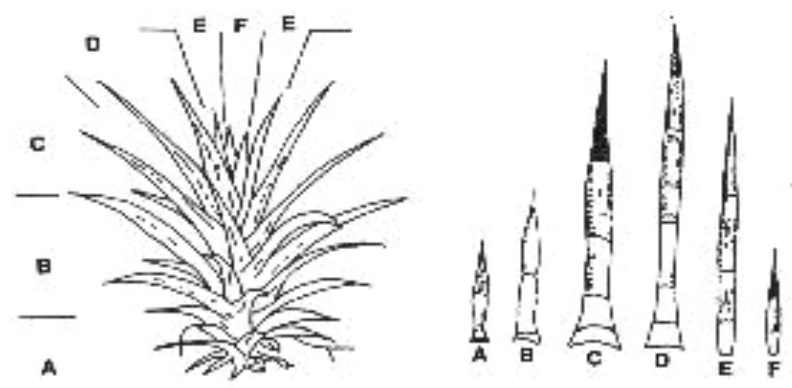

Figura 1 - Posição das folhas no caule de acordo com a idade.

Tabela 1 - Composição química e textural do substrato utilizado

\begin{tabular}{|c|c|c|c|c|c|c|c|c|}
\hline Areia & Argila & $\mathrm{pH}$ & $\mathrm{Ca}^{2+}$ & $\mathrm{Mg}^{2+}$ & $\mathrm{Al}^{3+}$ & $\mathrm{Na}^{+}$ & $\mathrm{K}$ & $P$ \\
\hline \multicolumn{2}{|c|}{$\left(\mathrm{g} \mathrm{kg}^{-1}\right)$} & $\left(\mathrm{H}_{2} \mathrm{O}\right)$ & \multicolumn{4}{|c|}{$\left(\mathrm{cmol}_{\mathrm{c}} \mathrm{dm}^{-3}\right)$} & \multicolumn{2}{|c|}{$\left(\mathrm{mg} \mathrm{dm}^{-3}\right)$} \\
\hline 810 & 170 & 7,2 & 2,2 & 2,3 & 0,0 & 0,26 & 1,518 & 18,70 \\
\hline
\end{tabular}

Análise realizada no Laboratório de Solos da UFRRJ, em Campos dos Goytacazes, RJ. 
de nutrientes utilizou-se a seguinte equação: $\mathrm{Y}=100-[(100 * \boldsymbol{a}) / \boldsymbol{b}]$, em que $\boldsymbol{a}$ é o conteúdo relativo de nutrientes na folha $\mathrm{D}$ nas densidades superiores a zero planta por vaso e b é o conteúdo relativo sob ausência de competição. Procedeu-se, portanto, para esta variável, apenas à análise descritiva, baseando-se no método usado por Ronchi et al. (2003).

Os efeitos dos tratamentos sobre o comprimento da folha $\mathrm{D}$ foram submetidos à análise de regressão, tendo sido também testados modelos lineares, considerando a avaliação realizada aos 90 DAT. Na seleção do melhor modelo foi utilizado como critério o maior valor do coeficiente de determinação em cada caso, além do modelo que melhor explicou o fenômeno biológico envolvido.

\section{RESULTADOS E DISCUSSÃO}

Verificou-se que, com a elevação do número das espécies daninhas (B. pilosa, C. rotundus e $D$. horizontalis) por recipiente, a quantidade de indivíduos que interferiram nos teores nutricionais da folha $\mathrm{D}$ do abacaxizeiro foi acrescida, refletindo, de forma geral, em maior competição exercida sobre as plantas de abacaxi, ou seja, maior percentual de redução relativa destes (Tabela 2 ).

Sob a densidade de 10 plantas por vaso, aos 30 DAT, as espécies apresentaram diferentes reduções nos teores nutricionais. Para C. rotundus não houve redução significativa nos teores de nitrogênio e fósforo, ao passo que o potássio foi reduzido em cerca de $20 \%$; já a presença de $B$. pilosa proporcionou maiores reduções nos teores de fósforo e magnésio, enquanto $D$. horizontalis extraiu mais fósforo e potássio sob esta densidade, em relação às demais espécies, provocando reduções acima de 20\%. Esses valores são mais expressivos à medida que se aumenta o número de indivíduos por vaso, acirrando a competição das espécies daninhas com o abacaxizeiro, podendo chegar a reduções próximas a $60 \%$ nos teores de fósforo quando se têm 40 plantas por vaso, o que equivale a aproximadamente 570 plantas $\mathrm{m}^{-2}$, considerando o recipiente com $0,3 \mathrm{~m}$ de diâmetro.

É sabido que a presença de plantas do gênero Cyperus aumenta a atividade de bactérias desnitrificantes na região da raiz, com conseqüente redução da disponibilidade de nitrogênio no solo (Ulbrich et al., 2004). Isso, em áreas com elevados teores desse nutriente, acarreta alta competitividade por parte da planta daninha, principalmente quando se aumenta a densidade desta (Santos et al., 1998). Das espécies avaliadas, C. rotundus foi a planta que apresentou maior competitividade com o abacaxizeiro por nitrogênio, sendo mais expressiva sob maior densidade (40 plantas por vaso). Além disso, quando se avalia a competição por cálcio, verifica-se que, aos 30 dias, tanto $C$. rotundus quanto $B$. pilosa causaram maior redução desse nutriente à medida que se aumentou a densidade delas.

A análise da interferência das plantas daninhas na fase inicial de crescimento do abacaxizeiro permite verificar que, sob densidade de 40 plantas por vaso, C. rotundus e $D$. horizontalis extraem maior porcentagem de fósforo e potássio do solo, em relação aos demais nutrientes analisados, enquanto plantas de $B$. pilosa extraem mais fósforo (Tabela 2).

A avaliação nutricional da folha $\mathrm{D}$ do abacaxizeiro é um bom indicativo para se detectar a necessidade de adubação nessa cultura (Siebeneichler et al., 2002); contudo, a distribuição dos nutrientes minerais na planta provavelmente não é homogênea e, mesmo ao longo das folhas, podem ocorrer teores diferenciados (Jones et al., 1991).

Com relação aos percentuais de redução relativa dos nutrientes aos 60 e 90 DAT, observaram-se discrepâncias nos mesmos; quando estes são comparados aos observados nos 30 primeiros dias, ou seja, em determinada situação, onde se esperava que, com o aumento da densidade das espécies daninhas, ocorreria redução nos teores nutricionais, foi verificado exatamente o oposto. Portanto, a avaliação da folha D não representou fidedignamente a interferência das plantas daninhas no abacaxizeiro, em função do aumento da densidade destas; segundo Christoffoleti \& Victória Filho (1996), o aumento da densidade das espécies daninhas intensifica a competição exercida sobre a cultura.

Trabalhos realizados por diversos autores, no entanto, têm demonstrado o efeito do 
Tabela 2 - Percentuais de redução relativa dos nutrientes na folha D do abacaxizeiro, em função da interferência de diferentes densidades de plantas daninhas, aos 30, 60 e 90 dias após o plantio do abacaxizeiro. Campos dos Goytacazes, 2001

\begin{tabular}{|c|c|c|c|c|c|c|c|c|c|c|c|c|c|c|c|c|}
\hline \multirow{2}{*}{ Espécie } & \multirow{2}{*}{$\begin{array}{c}\text { Densidade } \\
\text { (plantas } \\
\text { por vaso) }\end{array}$} & $\mathrm{N}$ & $\mathrm{P}$ & $\mathrm{K}$ & $\mathrm{Ca}$ & $\mathrm{Mg}$ & $\mathrm{N}$ & $\mathrm{P}$ & $\mathrm{K}$ & $\mathrm{Ca}$ & $\mathrm{Mg}$ & $\mathrm{N}$ & $\mathrm{P}$ & K & $\mathrm{Ca}$ & $\mathrm{Mg}$ \\
\hline & & \multicolumn{5}{|c|}{30 dias } & \multicolumn{5}{|c|}{60 dias } & \multicolumn{5}{|c|}{90 dias } \\
\hline \multirow{5}{*}{ 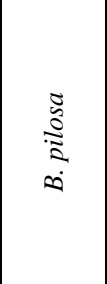 } & 0 & 0 & 0 & 0 & 0 & 0 & 0 & 0 & 0 & 0 & 0 & 0 & 0 & 0 & 0 & 0 \\
\hline & 10 & 9,3 & 13,2 & 2,9 & 4,1 & 11,9 & 11,2 & 2,1 & $-9,1$ & 24,8 & 15,9 & 5,8 & 31,6 & $-1,3$ & 31,5 & 24,7 \\
\hline & 20 & 12,6 & 26,3 & 1,0 & 18,2 & 6,8 & 7,0 & $-7,8$ & $-7,3$ & 4,4 & 5,2 & $-10,8$ & $-8,7$ & $-13,0$ & $-11,7$ & $-6,6$ \\
\hline & 30 & 18,6 & 46,6 & 26,0 & 28,3 & 24,3 & 16,8 & 43,5 & 18,3 & 5,7 & 15,5 & 14,2 & 31,0 & 21,0 & 23,4 & 18,1 \\
\hline & 40 & 19,7 & 58,7 & 27,9 & 36,4 & 29,4 & 0 & $-20,2$ & $\mid-19,9$ & $-0,9$ & 3,2 & 13,3 & 38,1 & 11,5 & 21,8 & 24,7 \\
\hline \multirow{5}{*}{ 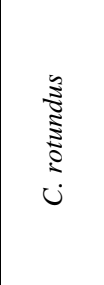 } & 0 & 0 & 0 & 0 & 0 & 0 & 0 & 0 & 0 & 0 & 0 & 0 & 0 & 0 & 0 & 0 \\
\hline & 10 & 0 & 0,4 & 18,3 & 12,7 & 6,8 & 25,2 & 37,8 & 23,9 & 10,4 & 23,8 & 21,7 & 47,4 & 22,0 & $-3,6$ & 24,0 \\
\hline & 20 & 8,7 & 27,4 & 22,1 & 21,4 & 4,7 & 22,4 & 40,3 & 35,4 & 11,8 & 10,3 & 31,7 & 32,2 & 3,3 & 29,4 & 25,7 \\
\hline & 30 & 33,0 & 45,1 & 43,3 & 31,2 & 37,5 & 21,7 & 42,2 & 38,6 & 5,7 & 31,0 & 24,2 & 22,2 & 9,5 & 2,8 & 1,7 \\
\hline & 40 & 35,8 & 57,5 & 55,8 & 32,4 & 39,6 & 53,9 & 47,0 & 36,8 & 17,0 & 36,9 & 29,2 & 52,9 & 21,7 & 33,9 & 42,4 \\
\hline \multirow{5}{*}{ 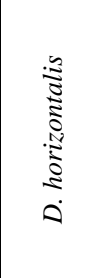 } & 0 & 0 & 0 & 0 & 0 & 0 & 0 & 0 & 0 & 0 & 0 & 0 & 0 & 0 & 0 & 0 \\
\hline & 10 & 17,5 & 29,7 & 22,1 & 5,5 & 11,9 & 9,8 & 35,1 & 27,4 & 32,6 & 28,5 & 2,5 & 53,9 & 32,2 & 39,5 & 33,0 \\
\hline & 20 & 25,8 & 60,5 & 51,0 & 10,1 & 21,3 & 11,2 & 68,2 & 51,1 & 10,0 & 43,7 & 3,3 & 73,0 & 48,9 & 12,9 & 41,0 \\
\hline & 30 & 24,1 & 60,5 & 50,0 & 7,2 & 28,1 & 21,0 & 59,7 & 41,9 & $-13,5$ & 23,4 & 9,2 & 60,9 & 38,1 & 9,7 & 30,9 \\
\hline & 40 & 33,0 & 57,1 & 51,9 & 33,0 & 31,5 & 22,4 & 60,6 & 49,2 & $-9,1$ & 34,9 & 24,2 & 68,8 & 52,7 & 12,9 & 46,5 \\
\hline
\end{tabular}

aumento da densidade de espécies daninhas sobre algumas variáveis de crescimento das culturas, como biomassa seca de parte aérea (Erasmo et al., 2003), altura (Fleck et al., 2000), área foliar (Salgado et al., 2002), produção de frutos (Morales-Payan et al., 1997), entre outras. Conforme os resultados apresentados na Figura 2, observa-se que a competição exercida por $C$. rotundus na cultura do abacaxi interfere de forma negativa no crescimento da folha $\mathrm{D}$; o aumento da densidade acentua a redução do comprimento desta, enquanto para $B$. pilosa e $D$. horizontalis aumentos na densidade acima de 30 plantas por vaso não resultaram em maiores decréscimos do comprimento da folha $\mathrm{D}$, haja vista a interrupção do crescimento desta a partir desses valores, em função da plasticidade fenotípica das espécies daninhas.

A não-linearidade da resposta, ou seja, reduções no crescimento da folha $\mathrm{D}$ à medida que se aumenta a densidade das espécies daninhas, ocorre porque tanto B. pilosa quanto
D. horizontalis, em densidades elevadas, apresentaram menor impacto no crescimento do que quando elas se encontravam em densidades relativamente baixas. Esse tipo de relacionamento entre densidade e crescimento da cultura é causado pela disponibilidade de recursos finitos (Radosevich et al., 1997); em densidades muito baixas, o crescimento da cultura é determinado pelo número de indivíduos, mas, em densidades elevadas, quando a capacidade do ambiente em suprir recursos torna-se limitada, o crescimento final independe da densidade de plantas daninhas.

Em alguns casos, sob menores densidades de plantas daninhas, ocorrem incrementos, por exemplo, no rendimento de grãos da cultura (Florez et al., 1999; Rizzardi et al., 2003), devido ao efeito complementar entre as espécies, possibilitando algum tipo de interação positiva entre elas sob essa condição; além disso, pode estar envolvida, também, a menor habilidade competitiva dessas plantas daninhas e/ou condições de menor interferência 


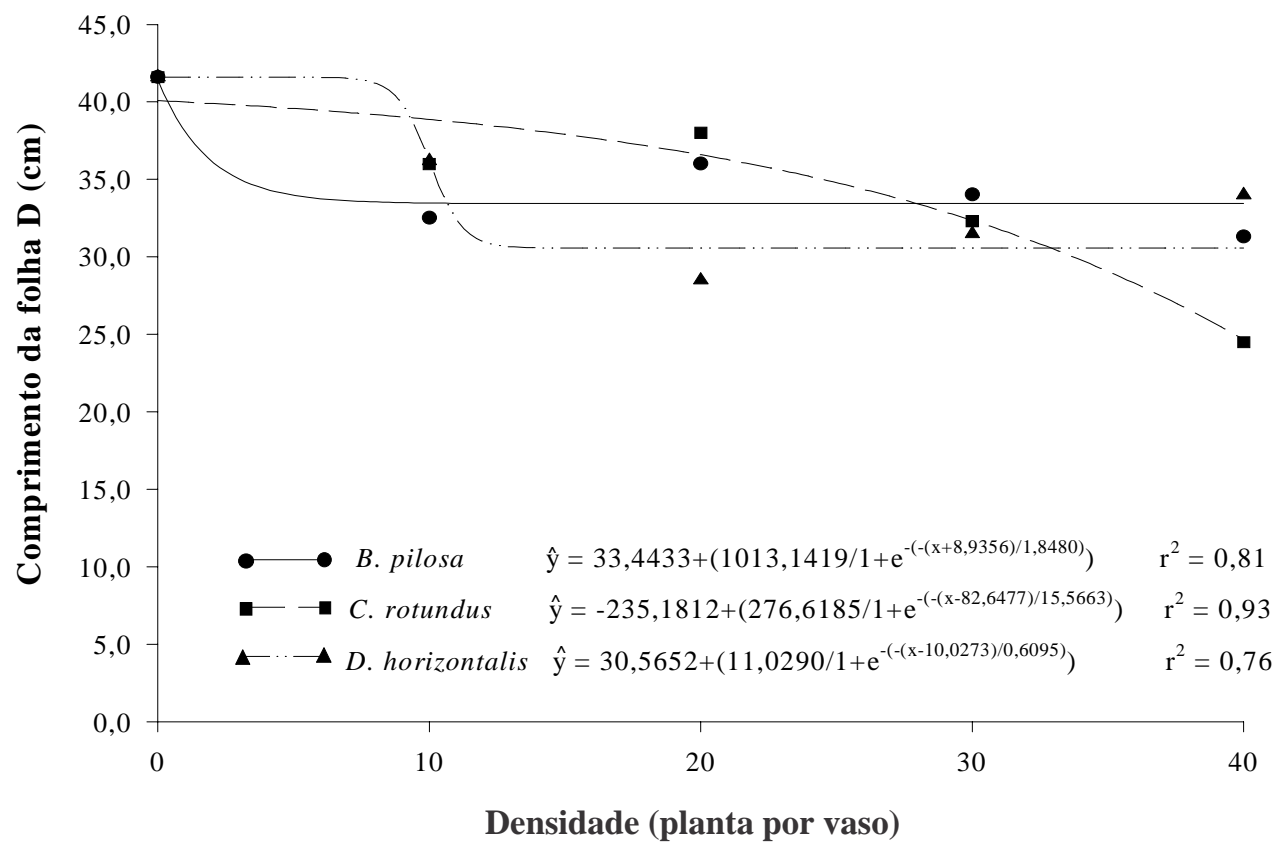

Figura 2 - Comprimento da folha D do abacaxizeiro $(\mathrm{cm})$, aos 90 dias após o plantio, em função da competição com plantas daninhas. Campos dos Goytacazes, 2001.

no crescimento da cultura. Já algumas espécies, como C. rotundus, se adaptam melhor a restrições do meio, como menor disponibilidade de nutrientes, em razão do seu alto poder de extração (Molares-Payan et al., 1998).

O grau de interferência variou com a espécie e com a densidade das plantas daninhas; $B$. pilosa e $C$. rotundus competiram mais com o abacaxizeiro aos 30 dias após o plantio, quando os teores de nitrogênio, fósforo e potássio na folha $\mathrm{D}$ reduziram em função da densidade destas; já aos 90 DAT constatou-se que o aumento da densidade resultou em redução do comprimento da folha $\mathrm{D}$, sob competição com C. rotundus. Verifica-se, portanto, que o fator densidade, aliado à espécie daninha, é de suma importância quanto à competição entre esta e a cultura de interesse. Além disso, a análise nutricional da folha $\mathrm{D}$, a partir de 30 dias, não foi um bom indicativo para se quantificar a capacidade competitiva da cultura por nutrientes.

\section{LITERATURA CITADA}

BULL, L. T.; ROSOLEM, C. A. Interpretação de análise química de solo e planta para fins de adubação. Botucatu: FEPAF, 1989. $360 \mathrm{p}$.
CHRISTOFFOLETI, P. J.; VICTÓRIA FILHO, R. Efeitos da densidade e proporção de plantas de milho (Zea mays L.) e caruru (Amaranthus retroflexus L.) em competição. Planta Daninha, v. 14, n. 1, p. 42-47, 1996.

CUNHA, G. A. P.; CABRAL, J. R. S.; SOUZA, L. F. S. O abacaxizeiro: cultivo, agroindústria e economia. Brasília: EMBRAPA, 1999. 480 p.

ELMORE, C. D.; PAUL, R. N. Composite list of $\mathrm{C}_{4}$ weeds. Weed Sci., v. 31, n. 5, p. 686-692, 1983.

ERASMO, E. A. L. et al. Efeito da densidade e dos períodos de convivência de Cyperus esculentus na cultura do arroz irrigado. Planta Daninha, v. 21, n. 3, p. 381-386, 2003.

FLECK, M. et al. Relação de interferência entre plantas daninhas e plantas de soja: efeitos de ervas dicotiledôneas em características da cultura. In: SALÃO DE INICIAÇÃO CIENTÍFICA, 12., 2000, Porto Alegre. Anais... Porto Alegre: UFRGS, 2000. p. 95.

FLOREZ, J. A. et al. Predicting rice yield losses caused by multispecies weed competition. Agron. J., v. 91, n. 1, p. 87-92, 1999.

JONES JR., J. B.; WOLF, B.; MILLS, H. A. Plant analysis handbook: a pratical sampling, preparation, analysis, and interpretation guide. Athens: Micro-Macro Publishing, 1991. $213 \mathrm{p}$. 
MACIEL, C. D. G.; CONSTANTIN, J.; GOTO, R.

Seletividade e eficiência agronômica de herbicidas no controle de capim-colchão na cultura da melancia. Hortic. Bras., v. 20, n. 3, p. 474-476, 2002.

MILLS, H. A.; JONES JR., J. B. Plant analysis handbook. II - A practical sampling, preparation, analysis, and interpretation guide. Athens: Micro-Macro Publishing, 1996. $422 \mathrm{p}$.

MOLARES-PAYAN, J. P. et al. Effects of purple nutsedge(Cyperus rotundus) on tomato (Lycopersicon esculentum) and bell pepper (Capsicum annuum) vegetative growth and fruit yield. Weed Technol., v. 11, n. 4, p. 672-676, 1997.

MOLARES-PAYAN, J. P. et al. Interference of purple nutsedge (Cyperus rotundus) population densities on bell pepper (Capsicum annuum) yield as influenced by nitrogen. Weed Technol., v. 12, n. 2, p. 230-234, 1998.

PROCÓPIO, S. O. et al. Absorção e utilização do nitrogênio pelas culturas da soja e do feijão e por plantas daninhas.

Planta Daninha, v. 22, n. 3, p. 365-374, 2004.

QUAYYUM, H. A. et al. Growth inhibitory effects of nutgrass (Cyperus rotundus) on rice (Oryza sativa) seedlings. J. Chem. Ecol., v. 26, n. 9, p. 2221-2231, 2000.
RADOSEVICH, S.; HOLT, J.; GHERSA, C. Associations of weeds and crops. In: Weed ecology - implications for management. 2.ed. New York: Wiley \& Sons, 1997. p. 163214.

RIZZARDI, M. A. et al. Perdas de rendimento de grãos de soja causadas por interferência de picão-preto e guanxuma. Ci. Rural, v. 33, n. 4, p. 621-627, 2003.

RONCHI, C. P. et al. Acúmulo de nutrientes pelo cafeeiro sob interferência de plantas daninhas. Planta Daninha, v. 21, n. 2 , p. $219-227,2003$.

SALGADO, T. P.; ALVES, P. L. C. A.; ROSSI, C. V. S. Efeito da densidade de tubérculos de tiririca (Cyperus rotundus) sobre o crescimento inicial de plantas da algodão. Planta Daninha, v. 20, n. 3, p. 405-411, 2002.

SANTOS, B. M. et al. Influence of purple nutsedge (Cyperus rotundus) density and nitrogen rate on radish (Raphanus sativus) yield. Weed Sci., v. 46, n. 6, p. 661-664, 1998.

SIEBENEICHLER, S. C. et al. Composição mineral da folha em abacaxizeiro: efeito da parte da folha analisada. R. Bras. Frutic., v. 24, n. 1, p. 194-198, 2002.

ULBRICH, A. V. et al. Ação do imazapic + imazapyr sobre a tiririca (Cyperus rotundus) e os desnitrificadores em milho. Planta Daninha, v. 22, n. 4, p. 577-582, 2004. 